\title{
Downregulation of Drosha, Dicer, and DGCR8 mRNAs in Peripheral Blood Mononuclear Cells of Patients with Rheumatoid Arthritis
}

\author{
Maassoumeh Akhlaghi ${ }^{1}$, Samaneh Soltani ${ }^{1}$, Fatemeh Jamshidi ${ }^{1}$, Seyedeh Tahereh Faezi ${ }^{1}$, Saeed Aslani ${ }^{1}$, \\ Shiva Poursani ${ }^{1}$, Ahmadreza Jamshidi', Mahdi Mahmoudi ${ }^{1 *}$
}

${ }^{1}$ Rheumatology Research Center, Tehran University of Medical Sciences, Tehran, Iran

Rheumatoid arthritis (RA) is a systemic autoimmune disorder causing irreversible joint damage. MicroRNAs (miRNAs) are post-transcriptional regulators of gene expression that degrade or translate inhibition of mRNAs. miRNAs can be used as therapeutic targets and predictive biomarkers in many disordres. This study was undertaken to investigate whether or not the expression of key elements in miRNA biogenesis, Drosha, DGCR8 and Dicer mRNAs is dysregulated in RA patients.

In this case-control study, 50 patients with RA and 50 age- and gender-matched healthy subjects participated. The peripheral blood mononuclear cells (PBMCs) were separated from the whole blood, the total RNA content of the cells was isolated and the first strand cDNA was synthesized. Quantitative analysis was performed through real-time polymerase chain reaction (PCR) using SYBR Green gene expression master mix to detect mRNA level expression of Drosha, DGCR8 and Dicer.

The expression levels of Drosha and DGCR8 were significantly downregulated in patients with RA in comparison with the healthy controls $(P$ value $=0.043, P$ value $=0.000365$, respectively). The expression level of Dicer was downregulated in RA patients when compared to the healthy controls, although the difference in expression was not significant $(P$ value $=0.156)$. RA patients with a familial history of autoimmune rheumatic disease recorded significant overexpression of all three genes. Moreover, DAS28 was significantly correlated with mRNA exoressiom of Drosha, Dicer and DGCR8.

The data suggests that downregulated expression of Drosha, DGCR8 and Dicer mRNAs may be contributing to the pathogenesis of RA.

Keywords: Rheumatoid arthritis; micro RNA; gene expression; Drosha; Dicer; DGCR8

\section{Introduction}

Rheumatoid arthritis (RA) is a systemic inflammatory autoimmune disorder characterized by progressive joint inflammation which affects tissues and organs. It is estimated that $1 \%$ of the world population is affected by RA and its prevalence is higher in females than in males [1]. This progresive disease terminates in systemic complications, disability, high medical and social costs, high morbidity and mortality rates and influences the quality of life [2]. The precise etiology of RA is not fully understood; however, it is thought that the interaction of genetic, immunological and environmental factors (such as smoking, hormones, infection and microbiota) contributes to development of the disease [3]. Genetic variants are thought to be responsible for $50 \%$ to $60 \%$ of the risk of developing RA [4]. Concordance rates among monozygotic and dizy- gotic twins for RA were estimated to be $12 \%$ to $15 \%$ and $3.5 \%$, respectively, suggesting the importance of genetics in the etiopathogenesis of the disease.

Epigenetics, the constant and inhereted changes in gene expression without alteration in DNA sequences [5] may also play a role in RA. Epigenetic processes include DNA methylation, histone modifications and microRNA (miRNA). miRNA is the single-stranded, highly conserved, noncoding and endogenous RNA of 20-22 nucleotides in length that bind to the $3^{\prime}$-untranslated region (3'-UTR) of their determined target genes and promote either translational prevention or mRNA degradation [6,7]. miRNAs have emerged as important regulators of the immune response, cell differentiation, cell cycle, apoptosis and immune functions [8-10]. They are believed to have crucial roles in the pathogenesis of human inflammatory arthritis

Personal non-commercial use only.Rheumatology Research Journal. Copyright (C 2018. All rights reserved

*Corresponding Author: Mahdi Mahmoudi, Ph.D., Rheumatology Research Center, Shariati Hospital, Kargar Ave., Tehran, Iran. Email: mahmoudim@tums.ac.ir, Tel/Fax: (+98)218-822-0067, PO-BOX: 1411713137.

Received: 23 May 2018; Accepted: 26 August 2018 
such as RA [11,16].

In the nucleus, genes encoding miRNAs are transcribed to a long primary transcript (pri-miRNAs; several hundred nucleotides) by the action of RNA polymerase II/III. Pri-miRNA comprises a hairpin stem, terminal loop and 5' and 3' single-stranded RNA extensions [17]. Pri-miRNA undergoes two-step sequential processing. First, it is cropped into hairpin-shaped pre-miRNAs (60-70 nt stemloop structure) by the Drosha/DiGeorge syndrome critical region 8 (DGCR8 or Pasha) complex, the nuclear RNase III enzyme. The catalytic subunit of the microprocessor complex, a combination of Drosha and DGCR8 [18], is Drosha and DGCR8 stabilizes Drosha by a protein-protein interface and identifies the RNA substrate [19]. Transportation of the pre-miRNA from the nucleus to the cytoplasm is performed by the exportin-5 (Exp5) through the nuclear pore complex [12].

Next, the hairpin-shaped pre-miRNA is cut by cytoplasmic RNase III Dicer/TAR-RNA binding protein (TRBP) complex, which removes the hairpin loop and generates $\sim 22$ nt of unstable mature miRNA duplex [20, 21]. A single strand of the miRNA duplex is incorporated into a 200-500 $\mathrm{kD}$ of ribonucleoprotein effector complex known as the RNA-induced silencing complex (RISC). This complex has endonuclease activity and is capable of modulating gene expression. [22].

The dysregulated expression profiles of some miRNAs display downregulation of miR-124a in RA synovium tissue, upregulation of miR-146a, miR-155, miR-203 in RA synovium tissue, miR-16, miR-132, miR-146, miR-155 in RA peripheral blood mononuclear cells (PBMCs) and overexpression of miR-223 in RA CD4 ${ }^{+}$naive T cells [12]. miRNAs appear to be promising biomarkers in a large panel of diseases, such as RA [23], which is why many studies have concentrated on the involvement of miRNAs on RA development. As the intracellular role of miRNAs is closely related to the function of Drosha, DGCR8 and Dicer, the present study investigated whether or not the expression level of Drosha and Dicer (as main miRNA machinery enzymes) and DGCR8 (as a microprocessor complex component) in PBMCs is involved in the pathogenesis of RA. The results may help achive a better understanding of the disease pathogenesis and contribute to the development of novel therapeutic strategies for RA.

\section{Materials and Methods}

\section{Study design}

The RA patients were recruited from the Rheumatolo- gy Research Center of Shariati Hospital in Tehran, Iran. All patients were diagnosed as having RA according to American College of Rheumatology criteria [24]. Fifty RA patients and 50 age- and gender-matched healthy controls without RA or other autoimmune diseases were enrolled in the study. The control group had a normal range of erythrocyte sedimentation rate (ESR). A standard questionnaire was used to collect information regarding age, age at RA diagnosis, symptoms and drug treatment. The Human Research Ethics Committees of Tehran University of Medical Sciences reviewed and approved this study. Informed consent forms were obtained from all subjects.

\section{Sample collection, PBMCs isolation and RNA extrac- tion protocols}

About $5 \mathrm{ml}$ of peripheral blood was collected from all participants under sterile conditions using venipuncture and was stored in EDTA anticoagulant. PBMCs were isolated using Ficoll-Hypaque density gradient centrifugation according to manufacture instructions. RNA extraction was carried out using a High Pure RNA isolation kit (Roche; Germany) according to manufacturer instructions. The purity and integrity of the extracted RNA was evaluated using a NanoDrop 2000c spectrophotometer (Thermo Fisher Scientific; USA) at 260/280 nm absorbance.

\section{Complementary DNA (cDNA) synthesis protocol}

Following RNA extraction from PBMCs, first strand cDNA was synthesized using the Transcriptor First Strand cDNA Synthesis Kit (Roche; Germany) according to manufacturer instructions. Briefly, $1 \mu \mathrm{g}$ of isolated RNA was reverse transcribed in a final volume of $20 \mu \mathrm{l}$ solution containing $2 \mu \mathrm{l}$ of primer (random hexamers) and RNase free water. Then the mixture incubated at $65^{\circ} \mathrm{C}$ for $10 \mathrm{~min}$ and cooled on ice. Next, $0.5 \mu \mathrm{l}$ of RNase inhibitor, $4 \mu \mathrm{l}$ of reaction buffer, $2 \mu \mathrm{l}$ of $\mathrm{dNTP}$ and $0.5 \mu \mathrm{l}$ of reverse transcription enzyme was added to the mixture. The reverse transcription conditions were as follows: $25^{\circ} \mathrm{C}$ for $10 \mathrm{~min}, 50^{\circ} \mathrm{C}$ for $60 \mathrm{~min}$ and $85^{\circ} \mathrm{C}$ for $5 \mathrm{~min}$. The cDNA samples were stored at $-20^{\circ} \mathrm{C}$ for later analysis.

\section{Real-time PCR primer design}

In this study, the primers were adapted from previously published studies by Sand et al. where mRNA expression of Drosha, Dicer and DGCR8 was measured in epithelial skin cancer subjects $[17,25]$. In order to check the accuracy and specificity of each primer, (Drosha, Dicer, DGCR8 and RPL38 as a housekeeping gene) the Basic Local Alignment Search Tool on the NCBI website was used [26]. Table 1 lists the details of each primer. 
Table 1. Primers used for real-time gene expression of Drosha, Dicer, and DGCR8

\begin{tabular}{|c|c|c|c|}
\hline Target & Sequence & Amplicon size (bp) & Temp $\left({ }^{\circ} \mathrm{C}\right)$ \\
\hline Drosha F & 5'-CATGTCACAGAATGTCGTTCCA-3' & 115 & 58.4 \\
\hline Drosha R & 5'-GGGTGAAGCAGCCTCAGATTT-3' & 115 & 59.8 \\
\hline Dicer F & 5'-TTAACCTTTTGGTGTTTGATGAGTGT-3' & 94 & 58.5 \\
\hline Dicer R & 5'-GGACATGATGGACAA TTTTCACA-3' & 94 & 57.1 \\
\hline DGCR8 F & 5'-GCAAGATGCACCCACAAAGA-3' & 93 & 57.3 \\
\hline DGCR8 R & 5'-TTGAGGACACGCTGCATGTAC-3' & 93 & 59.8 \\
\hline RPL38 F & 5'-TCACTGACAAAGAGAAGGCAGAGA-3' & 88 & 61 \\
\hline RPL38 R & 5'-TCAGTGTGTCTGGTTCATTTCAGTT-3' & 88 & 59.7 \\
\hline
\end{tabular}

\section{Quantitative real-time PCR}

Quantitative analysis was performed by quantitative PCR using the SYBR Green gene expression master mix (Takara Bio; Japan) and Step One Plus real-time PCR (Applied Biosystems; USA). The reaction mixture contained a total volume of $20 \mu \mathrm{l}$, including $10 \mu \mathrm{l}$ SYBR Green PCR master mix, $2 \mu \mathrm{l}$ primers ( $1 \mu \mathrm{l}$ each), $6 \mu \mathrm{l}$ RNase free water and 2 $\mu \mathrm{l}$ cDNA template. The conditions of mRNA Quantitative real-time PCR were as follows: $95^{\circ} \mathrm{C}$ for $30 \mathrm{sec}, 40 \mathrm{cy}-$ cles of $95^{\circ} \mathrm{C}$ for $15 \mathrm{sec}$ and $60^{\circ} \mathrm{C}$ for $1 \mathrm{~min}$. Evaluation of mRNA expression was performed using the comparative CT method previously explained by Livak and Schmittgen [27]. The relative quantification levels of the target $\mathrm{mR}$ NAs were normalized versus the RPL38 mRNA transcript level. Ultimately, the relative mRNA expression level for each sample was measured as: relative mRNA expression $=\left(2^{-\Delta C t}\right) \times 1000$.

\section{Statistical analysis}

SPSS software version 23 (SPSS; USA) was used to analyze the data. To assess normality, the KolmogorovSmirnov test was applied. Independent sample t-test or the Mann-Whitney U test was used to compare groups. For plotting, GraphPad Prism version 7.00 (GraphPad; USA; www.graphpad.com) was used. Scale data were expressed as mean \pm standard error of mean (SEM). Statistical significance was set at $P$ value $<0.05$.

\section{Results}

The study group comprised 50 RA individuals (9 men with a mean age of $54.66 \pm 12.58$ years and 41 women with a mean age of $45.85 \pm 8.88$ years) and 50 unrelated healthy controls. Table 2 provides the demographic specifications of the RA patients.

The expression level of Drosha was lower in the PBMCs of the RA patients ( 0.78 times downregulated) in comparison with the control group $(P$ value $=0.043$; Figure $1 \mathrm{~A})$. The DGCR8 expression level in PBMCs from RA patients was also 0.76 times downregulated compared to the controls $(P$ value $=0.000365$; Figure 1C). The Dicer expression level in PBMCs of RA patients decreased (0.54 times downregulated) compared to that of the control group (Figure 1B), although the expression difference was not statistically significant $(P$ value $=0.156)$.

The mRNA expressions of Drosha, Dicer, and DGCR8 were evaluated in the RA patients with respect to differences in clinicopathological and demographic specifications. Male versus female, smoker versus non-smoker, anti-cyclic citrullinated peptide (anti-CCP) positive versus anti-CCP negative RA patients did not show significant differences in the expression of these three genes. However, the rheumatoid factor (RF) positive RA patients demonstrated significant overexpression of Drosha mRNA in PBMCs in comparison with RF negative RA patients (fold change $=1.81 ; \quad P$ value $=0.03$ ) . 

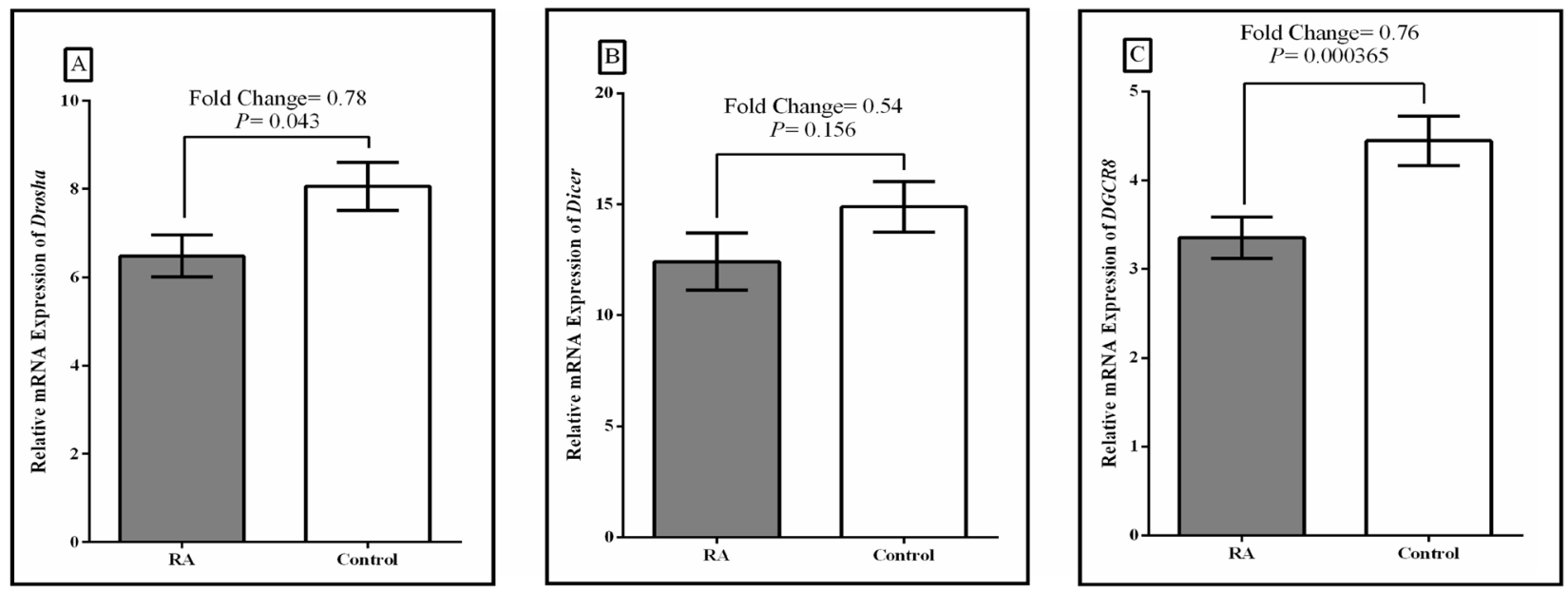

Figure 1. Comparison of relative expression in PBMCs of RA patients and healthy subjects of: (A) Drosha; (B) Dicer; (C) DGCR8.

There was also significant overexpression of Drosha (fold change $=1.89 ; P$ value $=0.003)$, Dicer $($ fold change $=1.66, P$ value $=0.049)$ and DGCR8 (fold change $=1.40$, $P$ value $=0.035)$ mRNAs in RA patients with a familial history of autoimmune rheumatic diseases in comparison with those patients without such a history (Figure 2, Table $3)$.
In correlation analysis (Figure 3), it was seen that age and ESR of RA patients did not correlate with the mRNA expression level of the three genes. However, the disease activity score for 28 joints (DAS28) correlated significantly with positive trends for mRNA expression levels of Drosha $(r=0.56, P$ value $<0.0001)$, Dicer $(r=0.47, P$ value $=0.0001)$ and DGCR8 $(r=0.31, P$ value $=0.027)$.

Table 2. Demographic data of RA patients

\begin{tabular}{lc}
\hline Characteristic & Value \\
\hline Gender & Female $(\mathrm{N}=41)$, Male $(\mathrm{N}=9)$ \\
Age \pm SD & $47.5 \pm 10.1$ \\
Age of diagnosis & $35.6 \pm 10.5$ \\
DAS28 & $3.5 \pm 2.0$ \\
ESR & $35.7 \pm 36.2$ \\
Smoking & $5(10.2 \%)$ \\
Familial history (autoimmune rheumatic disease) & $13(27.1 \%)$ \\
RF positive & $11(37.9 \%)$ \\
Anti-CCP positive & $7(25.9 \%)$ \\
Prednisolon & $17(34 \%)$ \\
HCQ & $17(34 \%)$ \\
SSZ & $9(18 \%)$ \\
MTX & $29(58 \%)$ \\
\hline
\end{tabular}

SD, standard deviation; DAS28, disease activity score for 28 Joints; ESR, Erythrocyte sedimentation rate; RF, Rheumatoid factor; CCP, cyclic citrullinated peptide; HCQ, Hydroxychloroquine; SSZ, Sulfasalazine; MTX, Methotrexate. 
Table 3. Differences in fold change and $P$ values of the expression levels of Drosha, Dicer, and DGCR8 based on different .category of patients for clinical specifications

\begin{tabular}{lcccccc}
\hline \multicolumn{2}{l}{ Groups } & \multicolumn{2}{c}{ Drosha } & \multicolumn{2}{c}{ Dicer } & \multicolumn{2}{c}{ DGCR8 } \\
& $\begin{array}{c}\text { Fold } \\
\text { change }\end{array}$ & $P$ value & $\begin{array}{c}\text { Fold } \\
\text { change }\end{array}$ & $P$ value & $\begin{array}{c}\text { Fold } \\
\text { change }\end{array}$ & $P$ value \\
\hline Male $v s$. Female & 1.01 & 0.96 & 0.89 & 0.59 & 1.04 & 0.88 \\
Smoker $v s$. Non-smoker & 0.81 & 0.43 & 0.95 & 0.96 & 0.95 & 0.83 \\
With familial history $v s$. without familial history & 1.89 & 0.003 & 1.66 & 0.049 & 1.40 & 0.035 \\
RF positive $v s$. RF negative & 1.81 & 0.03 & 1.73 & 0.11 & 1.40 & 0.10 \\
Anti-CCP positive $v s$. Anti-CCP negative & 1.53 & 0.59 & 2.12 & 0.41 & 1.22 & 0.99 \\
\hline RF, Rheumatoid factor; Anti-CCP, anti-cyclic citrullinated peptide & & & & &
\end{tabular}
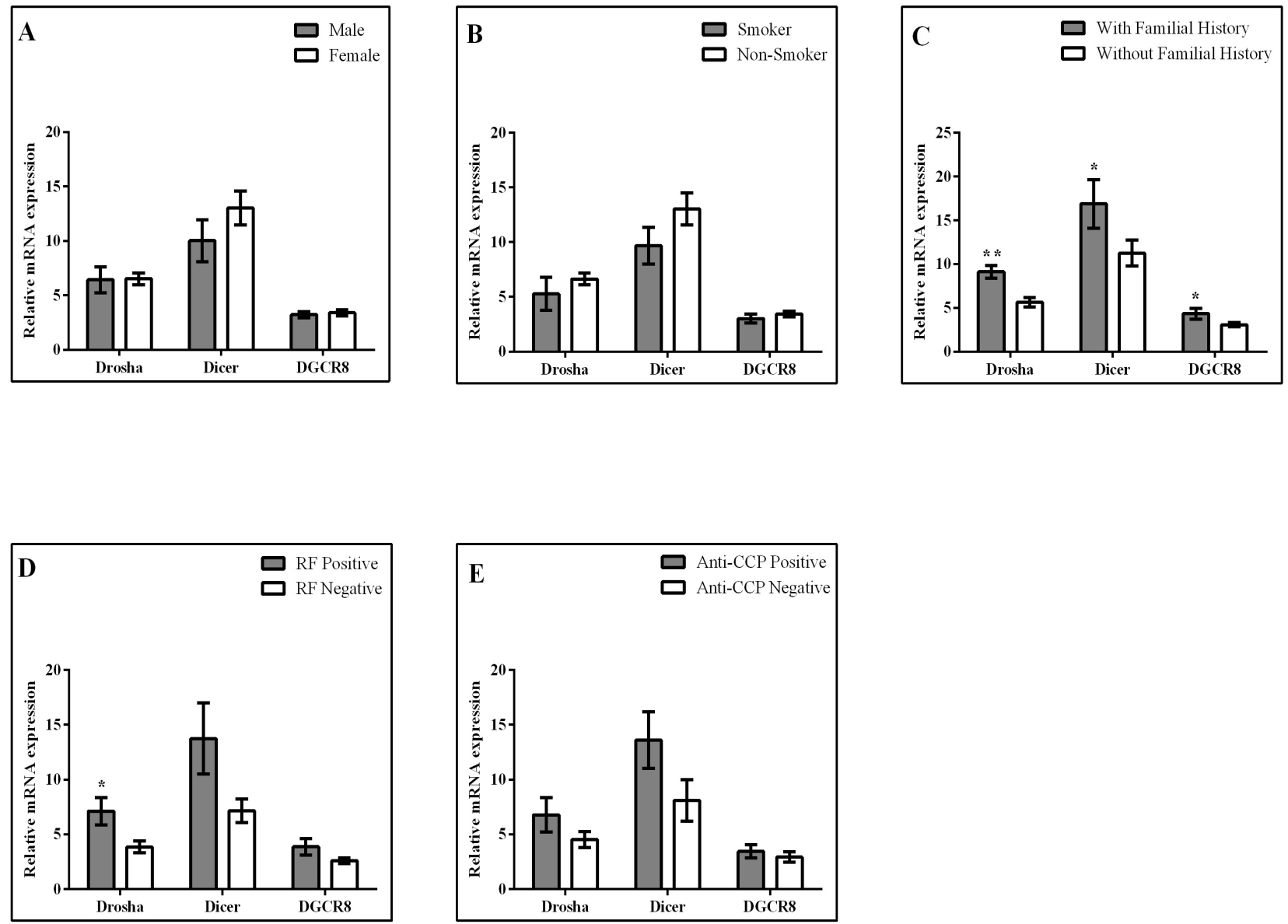

Figure 2. mRNA expression levels of Drosha, Dicer and DGCR8 in RA patients according to clinicopathological specifications of: (A) sex; (B) smoking; (C) familial history; (D), RF; (E) anti-CCP (* and ** implies to $P<0.05$, and $P<0.01$, respectively). 

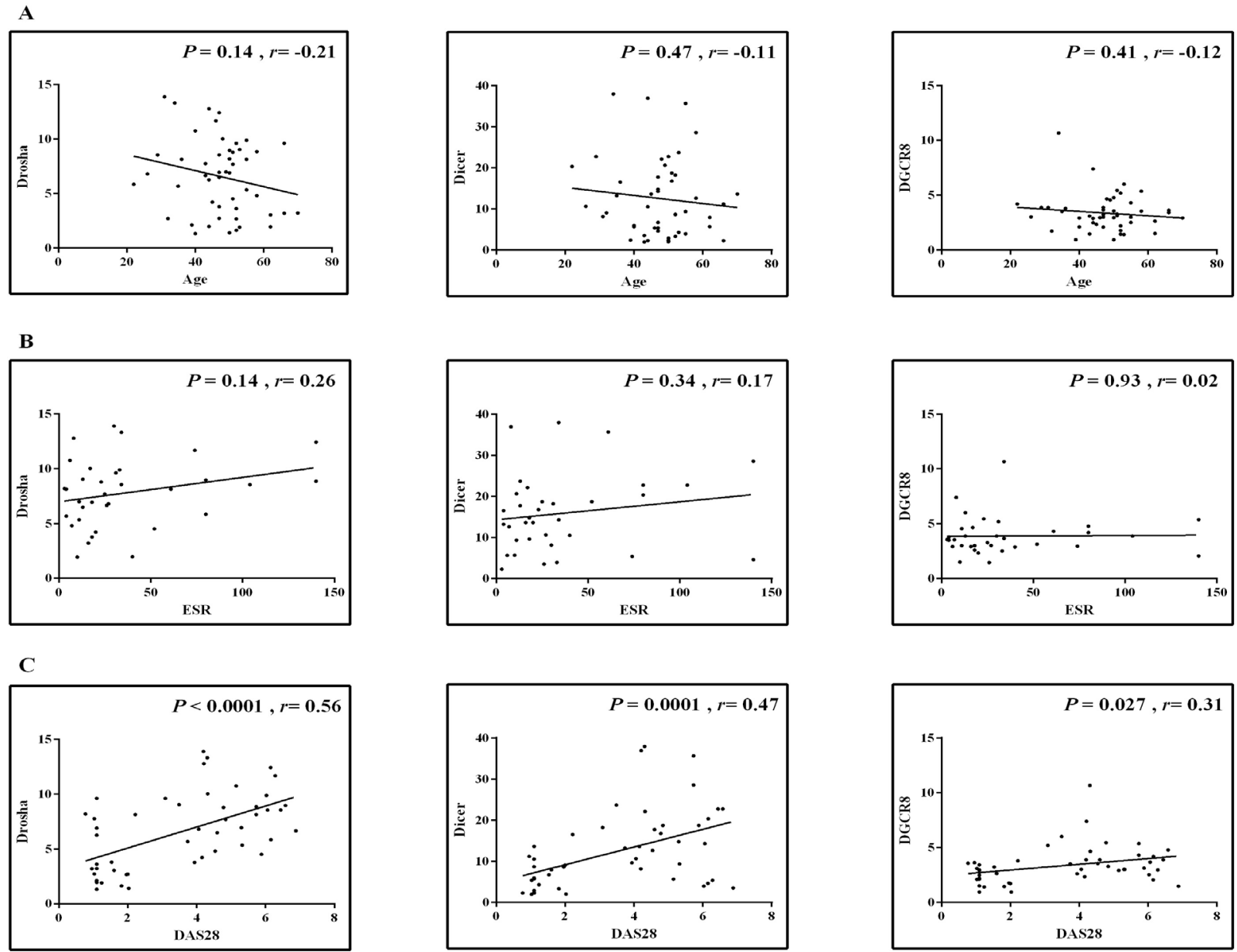

Figure 3. Correlation of mRNA expression levels of Drosha, Dicer, and DGCR8 with age (lane A), ESR (lane B) and DAS28 (lane C).

\section{Discussion}

Because previous reports have demonstrated that aberrant expression of miRNA in RA patients, we hypothesize that the elements involved in the synthesis of these molecules might also be dysregulated. To check this hypothesis, we examined the expression levels of Drosha, DGCR8 and Dicer in PBMC samples obtained from RA patients in comparison with healthy controls.

Epigenetics has provided a new orientation linking genetics and environmental factors. miRNA, as an epigenetic marker, has benefits for early stage detection of disease, prediction of disease progression and administration of appropriate treatment approaches; thus, it could serve as diagnostic and prognostic marker for many disorders [28]. miRNA functions as a post-translational regulator of gene expression and is known to be evolutionarily conserved between species [5].

It has been reported that miRNA plays an important role in many autoimmune diseases, including systemic lupus erythematous [29], multiple sclerosis (MS) [30], psoriasis [31] and sjögren's syndrome [32], suggesting a potential therapeutic target of miRNA in this group of disorders. Studies have documented dysregulation of various miRNAs in PBMCs [33, 34], serum [35], synovial tissue [36] and macrophages [37] in RA patients. For instance, the expression level of miR-146a, miR-155, miR-132 and miR16 increases in the PBMCs of RA patients in comparison with healthy control individuals [38].

miRNA machinery is a well-organized process which defines the biogenesis of miRNA [39]. In the pathway of miRNA biogenesis, molecules including Drosha, Dicer and DGCR8 have pivotal roles. Additionally, both Drosha and Dicer have critical roles in the function, differentiation and proliferation of $\mathrm{B}$ cells and regulatory $\mathrm{T}$ (Treg) cells and, therefore, play roles in immune regulation and pathogenesis of inflammatory disease. Loss of either Drosha or Dicer results in early onset lymphoproliferative disease 
and defective FoxP3 induction in Treg cells which leads to autoimmunity [40].

Results of a study have revealed downregulation of Drosha and Dicer in patients with Graves' disease and Hashimoto's disease, suggesting that low expression of these enzymes may cause reduced expression of miRNAs like miR-27b, miR-let7f, miR-21 and miR-98, which will increase the susceptibility to autoimmune thyroid disease [41]. Another study demonstrated significantly upregulation of Drosha, Dicer and DGCR8 in psoriasis patients in comparison with controls [42]. A study performed by Jafari et al. revealed significant upregulated expression of Drosha, Dicer and DGCR8 in MS patients in comparison with normal subjects and concluded that overexpression of these elements may contribute to the pathogenesis of MS [43]. These molecules were also dysregulated in patients with ankylosing spondylitis [44].

Our results show significant downregulation of mRNA expression levels of Drosha and DGCR8 in PBMCs of RA patients and the expression level of Dicer was slightly downregulated. These findings suggest that dysregulation of these major miRNA machinery elements may provide new insights for the possible contribution of these factors in RA pathogenesis. In contrast to our results, the study of Wang et al. found upregulated mRNA expression levels for Dicer and Drosha in RA patients. They concluded that the activation of Dicer led to suppression and balance of the production of tumor necrosis factor (TNF)- $\alpha$ and suggested that Dicer in RA patients functions as a regulator of immune responses [45]. The discrepancies observed between these two studies may stem from differences in sample sizes, ethnic backgrounds, inclusion and exclusion criteria, methodological approaches, statistical tests and even the effect of drugs and medications.

Array analysis demonstrated that, among the evaluated miRNAs, 91\% were overexpressed while 9\% were downregulated after anti-TNF $\alpha /$ disease-modifying antirheumatic drug (DMARD) combined therapy. Among the overexpressed miRNAs were miR-16-5p, miR-23-3p, miR125b-5p, miR-126-3p, miRN-146a-5p and miR-223$3 p$, which were only observed in responder patients [46]. This suggests that therapies in RA patients affect the level of miRNA and may regulate the components of miRNA biogenesis. Nonetheless, we were unable to assess the role of medications in modulating the major components of miRNA biogenesis because all of the patients had received at least one medication before being included in the study. Among the clinical characteristics of RA patients, familial history and RF status affected the mRNA expression of Drosha in PBMCs. The RF positive cases showed upregulated expression of Drosha. Moreover, the DAS28 level correlated with Drosha, Dicer and DGCR8 mRNA levels. To prematurely conclude from these observations that dysregulation of miRNA in RA patients (because of the altered level of enzymes in miRNA biogenesis like Drosha) may affect the disease activity (DAS28) and inflammatory status (RF) in patients.

There are some limitations and caveats with respect to the current study. It was conducted only on the PBMCs of RA patients and involved a limited number of patients; thus, it would be proper to conduct other studies with a larger number of participants using other types of samples, such as serum, synovial tissue and macrophages. It should also be noted that disease duration effects the epigenome of patients, especially those taking medication. Moreover, this was a cross-sectional study. A prospective study would be helpful in determining the possible role of environmental factors for the epigenome of patients by modulating miRNA levels, possibly through regulation of miRNA biogenesis components.

Overall, our data reveals that downregulation of key components of miRNA biogenesis, including Drosha, Dicer and DGCR8 is associated with disease activity level and inflammation status. Hence, these components may be involved in the pathogenesis of RA. There is a consensus that miRNAs modulate the inflammatory reactions in the joints and are biomarkers for inflammatory diseases and development of novel disease-modifying therapies. Hopefully, further studies can provide promising research orientations leading to novel insights into immunopathological mechanisms and development of new therapeutic approaches for RA patients.

\section{Acknowledgements}

The authors would like to thank all the participants for contributing to the completion of this study. This work was financially supported by a grant from the Deputy of Research of Tehran University of Medical Sciences (Grant No. 95-02-41-31189).

\section{Conflict of interest}

The authors declare no conflict of interest. 


\section{References}

1. Asadipour M, Hassan-Zadeh V, Aryaeian N, Shahram F, Mahmoudi M. Histone variants expression in peripheral blood mononuclear cells of patients with rheumatoid arthritis. International Journal of Rheumatic Diseases 2017. doi:10.1111/1756-185x.13126

2. Scott DL. Biologics-based therapy for the treatment of rheumatoid arthritis. Clin Pharmacol Ther 2012; 91(1):30-43. doi:10.1038/clpt.2011.278.

3. Xu WD, Zhang M, Zhang YJ, Ye DQ. IL-33 in rheumatoid arthritis: potential role in pathogenesis and therapy. Hum Immunol 2013; 74(9):1057-60. doi:10.1016/j.humimm. 2013.06.029.

4. Suzuki A, Yamada R, Chang X, Tokuhiro S, Sawada T, Suzuki M. et al. Functional haplotypes of PADI4, encoding citrullinating enzyme peptidylarginine deiminase 4, are associated with rheumatoid arthritis. Nat Genet 2003; 34(4):395-402. doi:10.1038/ng1206.

5. Brooks WH, Le Dantec C, Pers JO, Youinou P, Renaudineau Y. Epigenetics and autoimmunity. J Autoimmun 2010; 34(3):J207-19. 10.1016/j.jaut.2009.12.006.

6. Pillai RS. MicroRNA function: multiple mechanisms for a tiny RNA? $\boldsymbol{R} \boldsymbol{N A} 2005$; 11(12):1753-61. doi:10.1261/ rna.2248605.

7. Zisoulis DG, Kai ZS, Chang RK, Pasquinelli AE. Autoregulation of microRNA biogenesis by let-7 and Argonaute. Nature 2012; 486(7404):541-4.doi:10.1038/nature11134.

8. Chen CZ, Li L, Lodish HF, Bartel DP. MicroRNAs modulate hematopoietic lineage differentiation. Science 2004; 303(5654):83-6. doi:10.1126/science.1091903.

9. Xiao C, Rajewsky K. MicroRNA control in the immune system: basic principles. Cell 2009; 136(1):26-36. doi:10.1016/j.cell.2008.12.027.

10. Dooley J, Linterman MA, Liston A. MicroRNA regulation of T-cell development. Immunological reviews 2013; 253(1):53-64. doi:10.1111/imr.12049

11. Hussain N, Zhu W, Jiang C, Xu J, Wu X, Geng M. et al. Down-regulation of miR-10a-5p in synoviocytes contributes to TBX5-controlled joint inflammation. J Cell Mol Med 2017.doi:10.1111/jcmm.13312.

12. Furer V, Greenberg JD, Attur M, Abramson SB, Pillinger MH. The role of microRNA in rheumatoid arthritis and other autoimmune diseases. Clin Immunol 2010; 136(1):1-15.doi:10.1016/j.clim.2010.02.005.

13. Bogunia-Kubik K, Wysoczanska B, Piatek D, Iwaszko M, Ciechomska M, Swierkot J. Significance of Polymorphism and Expression of miR-146a and NFkB1 Genetic Variants in Patients with Rheumatoid Arthritis. Arch Immunol Ther Exp (Warsz) 2016; 64(Suppl 1):131-36. doi:10.1007/s00005-016-0443-5.

14. Balzano F, Deiana M, Dei Giudici S, Oggiano A, Pasella S, Pinna S. et al. MicroRNA Expression Analysis of Centenarians and Rheumatoid Arthritis Patients Reveals a Common Expression Pattern. Int J Med Sci 2017; 14(7):62228. doi:10.7150/ijms.18972.
15. Song GG, Bae SC, Seo YH, Kim JH, Choi SJ, Ji JD. et al. The association between susceptibility to inflammatory arthritis and miR-146a, miR-499 and IRAK1 polymorphisms. A meta-analysis. Z Rheumatol 2015; 74(7):63745. doi:10.1007/s00393-014-1493-x.

16. Chen ZZ, Zhang XD, Chen Y, Wu YB. The role of circulating miR-146a in patients with rheumatoid arthritis treated by Tripterygium wilfordii Hook F. Medicine (Baltimore) 2017;96(20):e6775.doi:10.1097/MD.0000000000006775.

17. Sand M, Gambichler T, Skrygan M, Sand D, Scola N, Altmeyer P. et al. Expression levels of the microRNA processing enzymes Drosha and dicer in epithelial skin cancer. Cancer Invest 2010; 28(6):649-53. doi:10.3109/07357901003630918.

18. Gregory RI, Chendrimada TP, Cooch N, Shiekhattar R. Human RISC couples microRNA biogenesis and posttranscriptional gene silencing. Cell 2005; 123(4):631-40. doi:10.1016/j.cell.2005.10.022.

19. Han J, Pedersen JS, Kwon SC, Belair CD, Kim YK, Yeom KH. et al. Posttranscriptional crossregulation between Drosha and DGCR8. Cell 2009; 136(1):75-84. doi:10.1016/j.cell.2008.10.053.

20. Han J, Lee Y, Yeom KH, Kim YK, Jin H, Kim VN. The Drosha-DGCR8 complex in primary microRNA processing. Genes Dev 2004; 18(24):3016-27.doi:10.1101/ gad.1262504.

21. Rostami Mogaddam M, Safavi Ardabili N, Shafaeei Y, Maleki N, Jafari N, Jafari A. Overexpression of Drosha, DiGeorge syndrome critical region gene 8 (DGCR8), and Dicer mRNAs in the pathogenesis of psoriasis. $\boldsymbol{J}$ Cosmet Dermatol 2017. doi:10.1111/jocd.12336.

22. Dalmay T. MicroRNAs and cancer. J Intern Med 2008; 263(4):366-75.doi:10.1111/j.1365- 2796.2008.01926.x.

23. Tavasolian F, Abdollahi E, Rezaei R, Momtazi-Borojeni AA, Henrotin Y, Sahebkar A. Altered Expression of MicroRNAs in Rheumatoid Arthritis. J Cell Biochem 2017. doi:10.1002/jcb.26205.

24. Arnett FC, Edworthy SM, Bloch DA, McShane DJ, Fries JF, Cooper NS. et al. The American Rheumatism Association 1987 revised criteria for the classification of rheumatoid arthritis. Arthritis Rheum 1988; 31(3):315-24. doi:10.1002/art.1780310302

25. Sand M, Skrygan M, Georgas D, Arenz C, Gambichler T, Sand D. et al. Expression levels of the microRNA maturing microprocessor complex component DGCR8 and the RNA-induced silencing complex (RISC) components argonaute-1, argonaute-2, PACT, TARBP1, and TARBP2 in epithelial skin cancer. Mol Carcinog 2012; 51(11):916-22. doi:10.1002/mc.20861.

26. Ye J, Coulouris G, Zaretskaya I, Cutcutache I, Rozen S, Madden TL. Primer-BLAST: a tool to design target-specific primers for polymerase chain reaction. BMC Bioinformatics 2012; 13:134. doi:10.1186/1471-2105-13-134.

27. Schmittgen TD, Livak KJ. Analyzing real-time PCR data by the comparative C(T) method. Nat Protoc 2008; 


\section{3(6):1101-8. doi:10.1038/nprot.2008.73}

28. Asadipour M, Hassan-Zadeh V, Aryaeian N, Shahram F, Mahmoudi M. Histone variants expression in peripheral blood mononuclear cells of patients with rheumatoid arthritis. Int J Rheum Dis 2017. doi:10.1111/1756185X.13126.

29. Zhu J, Huang X, Su G, Wang L, Wu F, Zhang T. et al. High expression levels of microRNA-629, microRNA-525-5p and microRNA-516a-3p in paediatric systemic lupus erythematosus. Clin Rheumatol 2014; 33(6):807-15. doi:10.1007/s10067-014-2583-5.

30. Otaegui D, Baranzini SE, Armananzas R, Calvo B, Munoz-Culla M, Khankhanian P. et al. Differential micro RNA expression in PBMC from multiple sclerosis patients. PLoS One 2009; 4(7):e6309. doi:10.1371/journal. pone.0006309.

31. Lovendorf MB, Mitsui H, Zibert JR, Ropke MA, Hafner M, Dyring-Andersen B. et al. Laser capture microdissection followed by next-generation sequencing identifies disease-related microRNAs in psoriatic skin that reflect systemic microRNA changes in psoriasis. Exp Dermatol 2015; 24(3):187-93.doi:10.1111/exd.12604.

32. Zilahi E, Tarr T, Papp G, Griger Z, Sipka S, Zeher M. Increased microRNA-146a/b, TRAF6 gene and decreased IRAK1 gene expressions in the peripheral mononuclear cells of patients with Sjogren's syndrome. Immunol Lett 2012; 141(2):165-8. doi:10.1016/j.imlet.2011.09.006.

33. Mookherjee N, El-Gabalawy HS. High degree of correlation between whole blood and PBMC expression levels of miR-155 and miR-146a in healthy controls and rheumatoid arthritis patients. J Immunol Methods 2013; 400401:106-10. doi:10.1016/j.jim.2013.10.001.

34. Tang X, Yin K, Zhu H, Tian J, Shen D, Yi L. et al. Correlation Between the Expression of MicroRNA-301a-3p and the Proportion of Th17 Cells in Patients with Rheumatoid Arthritis. Inflammation 2016; 39(2):759-67. doi:10.1007/ s10753-016-0304-8.

35. Filkova M, Aradi B, Senolt L, Ospelt C, Vettori S, Mann H. et al. Association of circulating miR-223 and miR-16 with disease activity in patients with early rheumatoid arthritis. Ann Rheum Dis 2014; 73(10):1898-904.10.doi:10.1136 annrheumdis-2012-202815.

36. Murata K, Yoshitomi H, Tanida S, Ishikawa M, Nishitani $\mathrm{K}$, Ito $\mathrm{H}$. et al. Plasma and synovial fluid microRNAs as potential biomarkers of rheumatoid arthritis and osteoarthritis. Arthritis Res Ther 2010; 12(3):R86.doi:10.1186/ $\operatorname{ar} 3013$.

37. Ogando J, Tardaguila M, Diaz-Alderete A, Usategui A, Miranda-Ramos V, Martinez-Herrera DJ. et al. Notch-regulated miR-223 targets the aryl hydrocarbon receptor path- way and increases cytokine production in macrophages from rheumatoid arthritis patients. Sci Rep 2016; 6:20223. doi:10.1038/srep20223.

38. Pauley KM, Satoh M, Chan AL, Bubb MR, Reeves WH, Chan EK. Upregulated miR-146a expression in peripheral blood mononuclear cells from rheumatoid arthritis patients. Arthritis Res Ther 2008; 10(4):R101. doi:10.1186/ ar2493.

39. Papachristou DJ, Korpetinou A, Giannopoulou E, Antonacopoulou AG, Papadaki H, Grivas P. et al. Expression of the ribonucleases Drosha, Dicer, and Ago2 in colorectal carcinomas. Virchows Arch 2011; 459(4):431-40. doi:10.1007/s00428-011-1119-5.

40. Chong MM, Rasmussen JP, Rudensky AY, Littman DR. The RNAseIII enzyme Drosha is critical in T cells for preventing lethal inflammatory disease. Journal of Experimental Medicine 2008; 205(9):2005-17. doi:10.1084/ jem.20081219

41. Saeki M, Watanabe M, Inoue N, Tokiyoshi E, Takuse Y, Arakawa Y. et al. DICER and DROSHA gene expression and polymorphisms in autoimmune thyroid diseases. Autoimmunity 2016; 49(8):514-22. doi:10.1080/08916934.2016.1230846

42. Rostami Mogaddam M, Safavi Ardabili N, Shafaeei Y, Maleki N, Jafari N, Jafari A. Overexpression of Drosha, DiGeorge syndrome critical region gene 8 (DGCR8), and Dicer mRNAs in the pathogenesis of psoriasis. Journal of Cosmetic Dermatology 2017.16(4):e48-53. doi:10.1111/ jocd. 12336

43. Jafari N, Shaghaghi H, Mahmoodi D, Shirzad Z, Alibeiki $\mathrm{F}$, Bohlooli S. et al. Overexpression of microRNA biogenesis machinery: Drosha, DGCR8 and Dicer in multiple sclerosis patients. Journal of Clinical Neuroscience 2015; 22(1):200-03. doi:10.1016/j.jocn.2014.06.106

44. Tabrizi Z, Mansouri R, Aslani S, Jamshidi A, Mahmoudi $\mathrm{M}$. Expression levels of the microRNA maturing microprocessor complex components; Drosha, Dicer, and DGCR8 in PBMCs from ankylosing spondylitis patients. Mediterranean Journal of Rheumatology 2017; 2(28):32-7.

45. Wang S, Yuan M, Song L, Zhang X, Geng Q, Zhang H. et al. Expression of Dicer in rheumatoid arthritis is associated with disease activity and balances the production of TNFalpha. Mol Med Rep 2017; 16(2):1590-95.doi:10.3892/ mmr.2017.6746.

46. Castro-Villegas C, Pérez-Sánchez C, Escudero A, Filipescu I, Verdu M, Ruiz-Limón P. et al. Circulating miRNAs as potential biomarkers of therapy effectiveness in rheumatoid arthritis patients treated with anti-TNF $\alpha$. Arthritis research \& therapy 2015; 17(1):49.doi:10.1186/s13075$015-0555-\mathrm{z}$ 